\title{
Numerical Studies on the Electronic Gadgets in a Personal Computer Using CFD
}

\author{
Murugan P. C. ${ }^{1}$, FathimaSurumy S. ${ }^{2}$, Joseph Sekhar S. ${ }^{3}$ \\ ${ }^{1,2,3}$ Department of Mechanical Engineering, St. Xavier's Catholic College of Engineering, Kanyakumari District, Tamilnadu, India
}

\begin{abstract}
The energy conservation of electronic components in computers is a very popular area of research for engineers because the temperature control inside the system unit of a desktop computer plays a vital role in its life and energy consumption. It is essential to study the various factors such as velocity of the inlet air, external temperature, heat generated in various components, heat transfer coefficient at various surfaces and orientation of components to overcome the design issues. In this paper, the three dimensional model of the system unit (SU) has been considered, and the temperature and velocity distribution inside the system unit, for the various operating conditions, have been analyzed using a CFD code ANYSYS-FLUENT 13. An experimental investigation has been carried out to validate the numerical approach.
\end{abstract}

Keywords: System Unit; CPU cooling;Personal Computer; Convective cooling; Heat transfer

\section{Introduction}

The rapid development in desktop personal computer is capable of processing more data which leads to an increase in the heat generation of components. Unless the heat is removed, the temperature of the devices will keep on increasing which leads to decrease in efficiency, and finally havoc to the components of the system unit may happen. Hence keeping the temperature of heat sources within the allowable limits has been a great challenge.

Many cooling techniques such as natural convection, forced convection, liquid cooling, immersion cooling and heat pipes are normally used for electronic-chip cooling. Of these the forced convection cooling is most commonly used, and with the help of CFD software packages several studies have been carried out in electronic systems. The FLOTHERM software has been used to solve the heat transfer issues in a PCB of a personal [1]. In the same time, Linton and Agonafer [2] have obtained an approximate temperature distribution of the PC heat transfer flow field with a single fan by utilizing PHOENICS. The finite volume technique together with staggered grid distribution and SIMPLEST algorithm is also employed. Moreover, Ronald and Dereje [3] have used CFD modelling to investigate the effect of finned heat sink used in the CPU cooling. Furthermore, a numerical heat transfer simulation about PowerPC 620 with processors is made using FLOTHERM [4]. Recently, Chang and Webb [5] have used finite element technique to analyse the system unit and obtained the minimum air flow rate for a desktop computer. The commercially available software, ANSYS ICEPACK is used to simulate a complete desktop computer system with $80 \mathrm{~W}$ CPU and other components such as memory, chipset, AGP, PCI cards and floppy drives. To decrease complexity CPU heat sink is modelled as a volume resistance having the same impendence as the detailed geometry. The cooling of PCI cards with PCI side vents and baffle, are improved by the analysis. Khan and Mahadevan [6] have shown that chassis with additional block can enhance the mixing of heat and cooling air by impinging effect. The suggestions implemented in a system unit, based on numerical studies, have resulted in $56 \%$ reduction of the surface temperature [7]. There has been much success in the thermal design of complex electronics system using CFD. FLOTHERM code has been used to simulate flow and temperature distribution of a computer chassis [8]. EmreOzturk and Ilker Tari [9] have drawn a CFD road map for the forced cooling conjugate heat transfer in a computer chassis. They obtained that the main sources of error in CFD study arise from inappropriate numerical, including turbulence model, radiation modeling and discretization schemes. ICEPACK is used for pre-processing and FLUENT is used for solution and post processing [10]. Rebaccaet. al. [11] used ICEPAK to investigate the pressure loss due to the presence of the inlet and outlet grilles. The fan curves obtained from the manufacturer are studied and suitable modifications are suggested to the manufacturers. Valerie et. al. [12] used FLOTHERM computations predicted the operating temperature of the components in an accuracy range of $3{ }^{\circ} \mathrm{C}$ to $22^{\circ} \mathrm{C}$. It is suggested that the source of error is due to inappropriate turbulence model.

\section{Simulation of System Unit}

The System unit of Desktop Computer is modeled in Solid Works. The Model includes the major heat generating components. It is modeled using the dimension of a common desktop personal computer with a height of $440 \mathrm{~mm}$, a width of $420 \mathrm{~mm}$ and a depth of $180 \mathrm{~mm}$ as shown in the Fig.1.The Components inside the System Unit are standard sized components which are used in most desktop computers. The chassis has small vents which are used to allow inlet air for cooling. The dimensions used in this study are given in Table1.The geometry of the 3D model is meshed with Tetragonal/Hybrid elements in Tgrid and imported in the CFD 


\section{International Journal of Science and Research (IJSR) \\ ISSN (Online): 2319-7064}

Index Copernicus Value (2013): 6.14 | Impact Factor (2015): 6.391

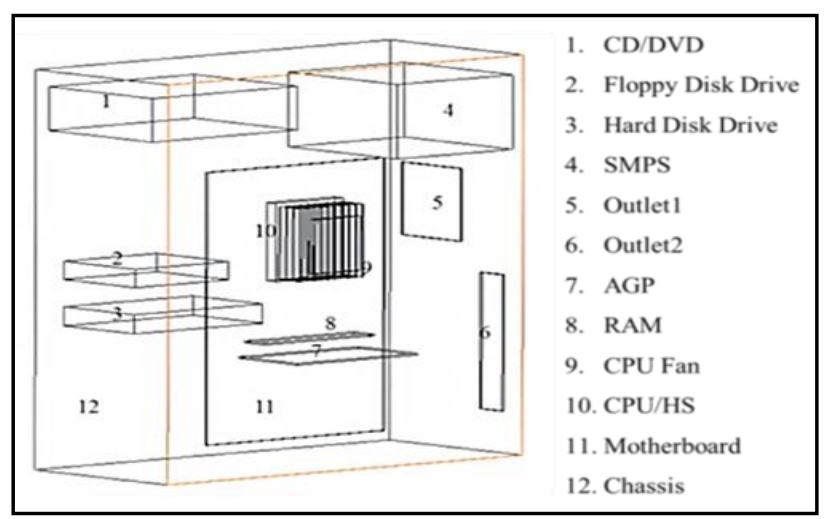

Figure 1: Schematic View of System Unit

Table 1: Specification of components inside SU

\begin{tabular}{|c|c|c|}
\hline Components & Dimensions $(\mathrm{m})$ & $\begin{array}{c}\text { Heat flux } \\
\left(\mathrm{W} / \mathrm{m}^{2}\right)\end{array}$ \\
\hline Chassis & $0.42 \times_{0.44 \times 0.18}$ & - \\
\hline CD/DVD & $0.048 \times 0.172 \times_{0.14}$ & 115.2 \\
\hline FDD & $0.02 \times_{0.11} \times_{0.097}$ & 337.61 \\
\hline HDD & $0.021 \times_{0.152} \times_{0.095}$ & 509.5 \\
\hline Motherboard & $0.3 \times_{0.21} \times_{0.002}$ & - \\
\hline CPU/HS & $0.045 \times 0.08 \times 0.86$ & 2439 \\
\hline AGP & $0.079 \times_{0.142} \times_{0.002}$ & 1072 \\
\hline RAM & $0.027 \times_{0.13} \times_{0.002}$ & 1307.5 \\
\hline SMPS & $0.082 \times_{0.137} \times_{0.147}$ & 863.5 \\
\hline
\end{tabular}

software FLUENT-13. The three dimensional equations for conservation of mass, conservation of momentum, and energy uses for numerical analysis are:

Conservation of Mass:

$$
\frac{\partial p}{\partial t}+\nabla(\rho V)=\frac{D p}{D t}+\rho \nabla \cdot V=0
$$

Conservation of Momentum Equation for an incompressible Fluid:

$$
\rho \frac{\mathrm{Du}}{\mathrm{Dt}}=\rho \mathrm{g}_{\mathrm{x}}-\frac{\partial \mathrm{P}}{\partial \mathrm{x}}+\mu\left(\Delta^{2} \cdot \mathrm{u}\right)
$$

Energy Equation:

$$
\left(u \frac{\partial T}{\partial x}+v \frac{\partial T}{\partial y}+w \frac{\partial T}{\partial z}\right)=\frac{1}{\alpha}\left(\frac{\partial^{2} T}{\partial y^{2}}+\frac{\partial^{2} T}{\partial z^{2}}\right)
$$

The well-known $\mathrm{k}$ - epsilon model is used for analysis. The Energy equation is enabled and the boundary conditions are given for each components based on heat transfer coefficients. The standard method is used for initializing the solution. The calculation was allowed to run until converges.

\section{Experimental Study}

An experimental study has been conducted in a System Unit to validate the results obtained from the simulation. The system unit has been modified to conduct the experimental study. On the outer cover, openings, with shutters, are made in few places to check surface temperature of the components. An infrared thermometer has been used for this purpose. Inside the unit RTD sensors are placed in few places to check the temperature distribution of the space, mainly at the outlet of the CPU fan, near the RAM, outlet of
SMPS fan and inlet openings, etc.,. The inlet air velocity of $\mathrm{SU}$ is measured experimentally by using the Anemometer. The ambient temperature and air velocity near the unit have been recorded. The entire system has been kept in the temperature controlled space to change the inlet air temperature and ambient conditions.

\section{Result and Discussion}

The numerical analysis of system unit has been carried out for various operating conditions such as ambient temperature, inlet velocity and convective heat transfer coefficient. With the post-processing facility in the software, the contour plots for the temperature and vector plot for velocity have been generated for various operating conditions. The results obtained from each node of the components at various operating conditions have been collected and plotted in graphs.

The variation in inlet air temperature plays a major role in the temperature distribution of SU. The Fig.2 represents how the temperature of each component in SU varies for inlet temperature conditions at an inlet velocity of $1.5 \mathrm{~m} / \mathrm{s}$. It is observed that, the increase in inlet temperature increases the component temperature in a linear profile. The temperature range for various components such as CPU, AGP, RAM, SMPS and HDD are $343 \mathrm{~K}$ to $350 \mathrm{~K}, 328 \mathrm{~K}$ to $336 \mathrm{~K}, 331$ to $338 \mathrm{~K}, 325 \mathrm{~K}$ to $333 \mathrm{~K}$ and $318 \mathrm{~K}$ to $325 \mathrm{~K}$ respectively. This shows that the inlet air temperature could be maintained less than $303 \mathrm{~K}$ for a good performance.

The variation in air inlet velocity influences the temperature distribution of SU and its components. Therefore, temperature and convective heat transfer coefficient are kept constant and the variation of temperature with respect to the inlet velocity has been is shown in Fig. 3. It is observed that the temperature of various components decreases significantly when the velocity is increased from $1 \mathrm{~m} / \mathrm{s}$ to $3 \mathrm{~m} / \mathrm{s}$, and the variation is not significant when the velocity increases above $3 \mathrm{~m} / \mathrm{s}$. This shows that the velocity could be maintained around $1.5 \mathrm{~m} / \mathrm{s}$ to $2 \mathrm{~m} / \mathrm{s}$ for a good performance. The temperature range for various components such as CPU, AGP, RAM, SMPS and HDD are $349 \mathrm{~K}$ to $340 \mathrm{~K}, 333 \mathrm{~K}$ to $326 \mathrm{~K}, 336 \mathrm{~K}$ to $328 \mathrm{~K}, 330 \mathrm{~K}$ to $323 \mathrm{~K}$ and $333 \mathrm{~K}$ to $326 \mathrm{~K}$ respectively.

The influence of natural convective heat transfer coefficient (CHTC) on the temperature distribution of the system unit has been studied and plotted in Fig. 4 to Fig.7. It is observed that the increase in the CHTC from 5 to $10 \mathrm{~W} / \mathrm{m}^{2} \mathrm{~K}$ reduces the temperature ( 7 to $12 \mathrm{~K}$ ) of major components. Therefore to achieve a good performance of $\mathrm{SU}$, the temperature and velocity can be maintained at $303 \mathrm{~K}$ to $306 \mathrm{~K}$ and $1.5 \mathrm{~m} / \mathrm{s}$ to 2 $\mathrm{m} / \mathrm{s}$ respectively. The theoretical and experimental value of temperature obtained from various components are compared in Table 2. Since the deviations of theoretical values are within $10 \%$ from experimental results, the validity of the approach is confirmed.

Table 2: Comparison of experimental and numerical results

\begin{tabular}{l|l|l} 
Components & Analysis value & Experimental Value
\end{tabular}

Proposed 


\section{International Journal of Science and Research (IJSR) \\ ISSN (Online): 2319-7064}

Index Copernicus Value (2013): 6.14 | Impact Factor (2015): 6.391

\begin{tabular}{|c|c|c|c|c|c|}
\hline & $\begin{array}{c}\text { Lowest Temperature } \\
(\mathrm{K})\end{array}$ & $\begin{array}{c}\text { Highest Temperature } \\
(\mathrm{K})\end{array}$ & $\begin{array}{c}\text { Lowest Temperature } \\
(\mathrm{K})\end{array}$ & $\begin{array}{c}\text { Highest Temperature } \\
(\mathrm{K})\end{array}$ & $\begin{array}{c}\text { Temperature } \\
(\mathrm{K})\end{array}$ \\
\hline AGP & 324 & 345 & 321 & 347 & $323-342$ \\
\hline CPU/HS & 337 & 360 & 342 & 364 & $346-374$ \\
\hline FDD & 312 & 332 & 318 & 335 & $309-338$ \\
\hline HDD & 314 & 334 & 320 & 336 & $312-333$ \\
\hline RAM & 325 & 347 & 331 & 348 & $328-343$ \\
\hline SMPS & 321 & 341 & 327 & 343 & $318-343$ \\
\hline
\end{tabular}

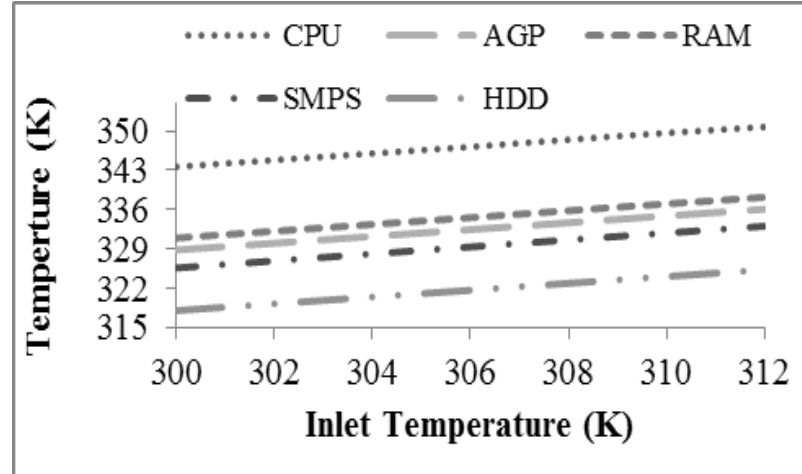

Figure 2: Temperature variations in component for various inlet temperatures

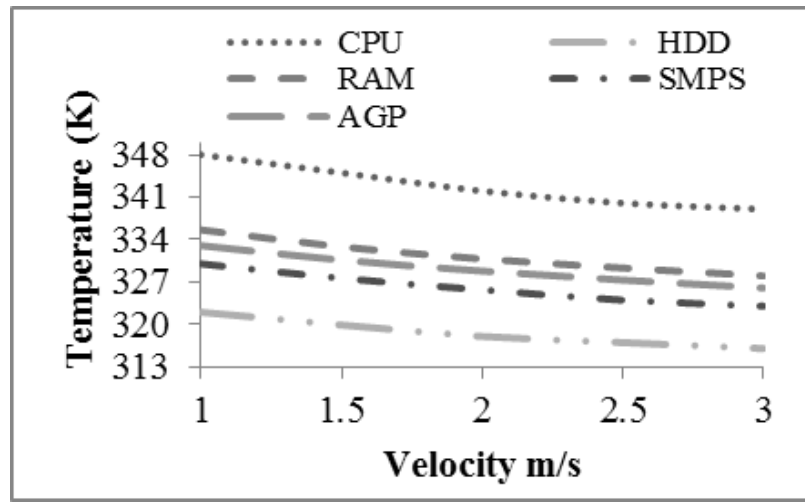

Figure 3: Temperature variations in component for various inlet velocity

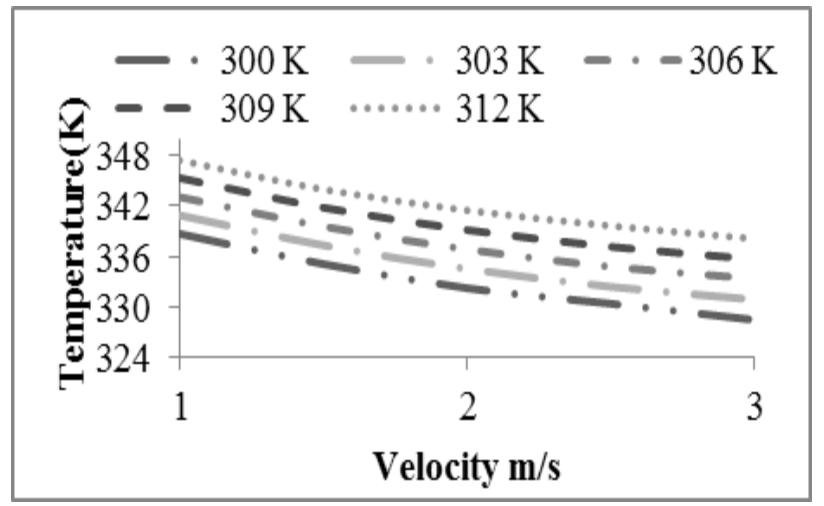

Figure 4: Temperature variation in $\mathrm{CPU}$ at $\mathrm{CHTC}$ of 5 $\mathrm{W} / \mathrm{m}^{2} \mathrm{~K}$

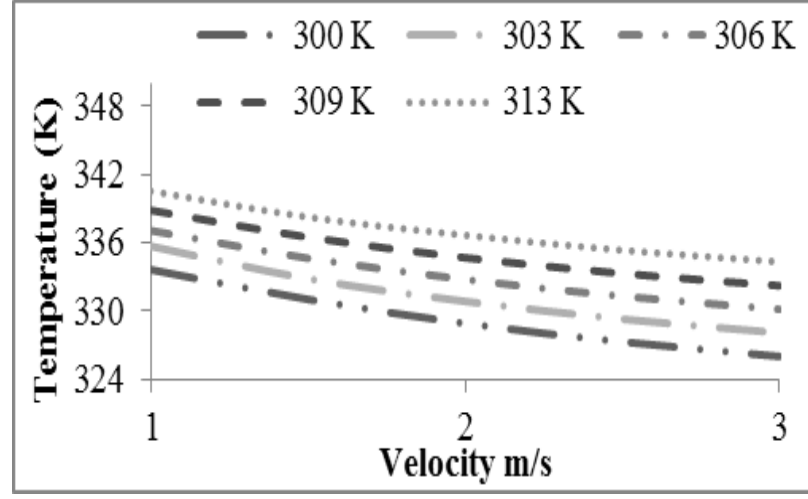

Figure 5: Temperature variation in CPU at CHTC of 10 $\mathrm{W} / \mathrm{m}^{2} \mathrm{~K}$

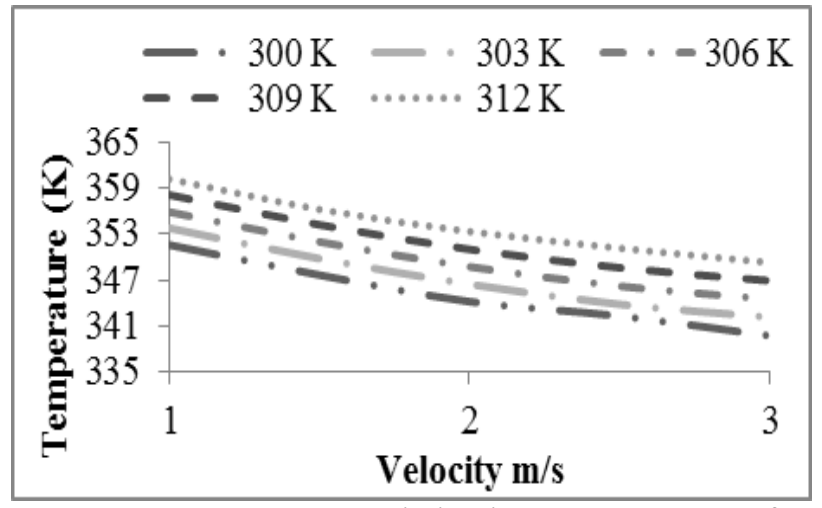

Figure 6: Temperature variation in RAM at CHTC of 5 $\mathrm{W} / \mathrm{m}^{2} \mathrm{~K}$

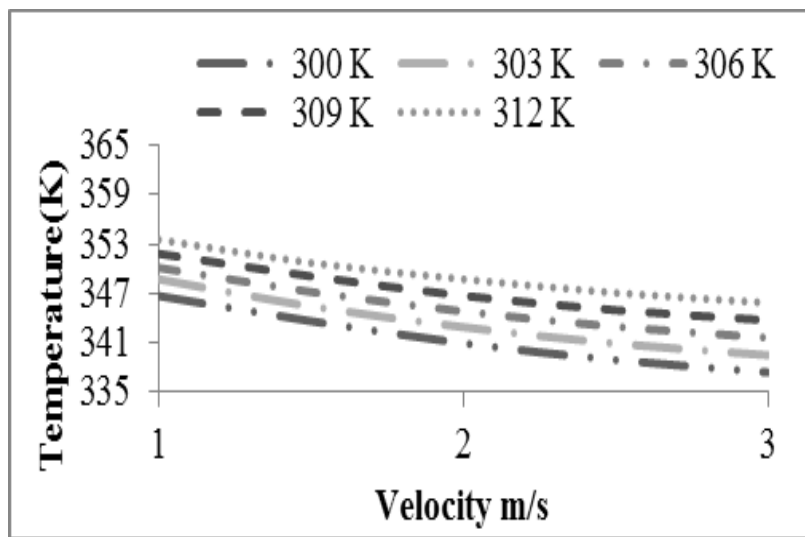

Figure 7: Temperature variation in RAM at CHTC of 10 $\mathrm{W} / \mathrm{m}^{2} \mathrm{~K}$

\section{Conclusion}

The flow patterns observed in this study are close to the similar ones reported in the literature. Moreover the experimental values and simulated results are close to each other. Since the velocity variation is observed with respect to the change in other parameters. The position of the cooling

\section{Volume 5 Issue 7, July 2016} www.ijsr.net 
fan and velocity of the cooling air plays an important role. The influence of temperature in System unit is one of the major factors; the result proves that for a good performance the temperature could be maintained less than 306K.Hence for a good performance the air inlet velocity could be maintained around $1.5 \mathrm{~m} / \mathrm{s}$ to $2 \mathrm{~m} / \mathrm{s}$. It is predicted that the, natural convective heat transfer coefficient is more appropriate than the adiabatic condition. Therefore while selecting a SU for any desktop personal computer, this type of analysis can be used to fix the position of various components inside the System Unit.

\section{References}

[1] T.Y. Lee, and M. Mahalingam, - Aplication of a CFD Tool for System Level Thermal Simulation", IEEE Transactions on Components, Packaging and Manufacturing Technology_Part A, Vol. 17, No. 4, 1994, pp. 564-572.

[2] R.L. Linton, D. Agonafer., - Thermal model of a PC", ASME Journal of Electronic Packaging,Vol. 116, pp 134-137, 1994.

[3] R.L. Linton and D. Agonafer, Coarse and detailed CFD modeling of a finned heat sink", IEEE Transactions on Components, Packaging and Manufacturing Technology, Part A 18 (1995) 517.

[4] H. Wong, T. Yu and T. Lee, IEEE Transactions on Components, Packaging and Manufacturing Technology, Part A 19 (4) (1996) 82.

[5] C.W. Yu and R.L.Webb., Thermal Design of a Desktop computer system using CFD analysis," Seventeenth IEEE Semi-Therm Symposium, pp. 18-26, 2001.

[6] N. Khan, D. Pinjala, and M.K. Iyer, Liu Baomin ; R. Mandal, and Y.C. Mui, - Thermal analysis of IC package burn-in subrack", International Conference on Electronics packaging technology (2002) 366 - 370 .

[7] C.W. Argento, Y. K. Joshi and M. D. Osterma., -Fored convection air cooling of a commercial electronic chassis: an experimental and computational case study", IEEE transactions on Components, Packaging and Manufacturing Technology, Part A 19(2), 248-257, 1996.

[8] ANSYS-FLUENT theory guide. ANSYS release 14.0. ANSYS. Inc.

[9] Emre Ozturk and Ilker Tari, - CE modelling of forced cooling of computer chassis Engineering Applications of Computational Fluid Dynamics Vol.1, No. 4, pp.304313, 2007.

[10]Emre Ozturk and Ilker Tari, Forced Air Cooling of CPUs with Heat sinks: a Numerical Study", IEEE Transactions on Components and Packaging Technologies, Vol. 31, No.3, pp.650-660, 2008.

[11] Rebecca Biswas, B. Raghu. Agarwal, Avijit Goswami and Vivek Mansingh, Evaluation of airflow prediction methods in compact electronic enclosures," Fifteenth IEEE Semi-Therm Symposium, pp. 48-53, 1999.

[12] Valerie Eveloy, Peter Rodgers, and M. S. J. Hashmi, Numerical Prediction of Electronic Component heat transfer: An industry perspective", Proceedings of 19th SEMI-THERM San Jose USA, 14-26, 2003.

Volume 5 Issue 7, July 2016 www.ijsr.net 